\title{
Hyaluronan Depolymerization by Megakaryocyte Hyaluronidase-2 Is Required for Thrombopoiesis
}

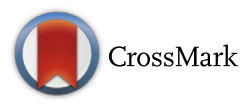

\author{
Aaron C. Petrey, ${ }^{*}$ Dana R. Obery, ${ }^{*}$ Sean P. Kessler, ${ }^{*}$ Bruno Flamion, ${ }^{\dagger}$ and Carol A. de la Motte*
}

From the Department of Pathobiology, ${ }^{*}$ Cleveland Clinic Lerner Research Institute, Cleveland, Ohio; and the Molecular Physiology Research Unit, ${ }^{\dagger}$ Namur Research Institute for the Life Sciences, University of Namur, Namur, Belgium

Accepted for publication

May 10, 2016.

Address correspondence to

Carol A. de la Motte, Ph.D., Department of Pathobiology, NC22, Cleveland Clinic Lerner Research Institute, 9500 Euclid Ave., Cleveland, OH 44195.

E-mail: delamoc@ccf.org.

\begin{abstract}
Hyaluronan is the predominant glycosaminoglycan component of the extracellular matrix with an emerging role in hematopoiesis. Modulation of hyaluronan polymer size is responsible for its control over cellular functions, and the balance of hyaluronan synthesis and degradation determines its molecular size. Although two active somatic hyaluronidases are expressed in mammals, only deficiency in hyaluronidase-2 (Hyal-2) results in thrombocytopenia of unknown mechanism. Our results reveal that Hyal-2 knockout mice accumulate hyaluronan within their bone marrow and within megakaryocytes, the cells responsible for platelet generation. Proplatelet formation by Hyal-2 knockout megakaryocytes was disrupted because of abnormal formation of the demarcation membrane system, which was dilated and poorly developed. Importantly, peptide-mediated delivery of exogenous hyaluronidase rescued deficient proplatelet formation in murine and human megakaryocytes lacking Hyal-2. Together, our data uncover a previously unsuspected mechanism of how hyaluronan and Hyal-2 control platelet generation. (Am J Pathol 2016, 186: 2390-2403; http://dx.doi.org/10.1016/j.ajpath.2016.05.004)
\end{abstract}

Platelets are small anucleated cells produced within the bone marrow (BM) by megakaryocytes (MKs) in a process that requires significant cellular changes. ${ }^{1}$ As an MK matures from a progenitor cell, it becomes polyploid and expands substantially in size. ${ }^{2-4}$ Within the MK, the cytoplasm and membrane are remodeled, leading to the formation of the demarcation membrane system (DMS). Through a network of tubular invaginations of the plasma membrane, the DMS defines the source of nascent platelets. ${ }^{5-7}$ Mature MKs migrate to the BM sinusoids and extend long cytoplasmic proplatelet extensions through the vascular wall, releasing hundreds of platelets into circulation. ${ }^{8-11}$

Hyaluronan (HA) is a large, space-filling, hydrating, abundant glycosaminoglycan and is a major component of the extracellular matrix. ${ }^{12,13}$ Produced by the HA synthase (HAS) enzymes (HAS 1 to 3), HA can be released into the extracellular matrix or remain tethered to the cell surface by HASs and HA receptors. ${ }^{14}$ HA exerts a broad spectrum of effects on cells dictated by its size and interaction with specific glycoprotein receptors, including CD44, Toll-like receptor (TLR)-4, and receptor for HA-mediated motility (RHAMM). ${ }^{15-17}$ Under normal physiologic conditions in tissues, HA is present in a high-molecular-weight form $\left(10^{6}\right.$ to $\left.10^{7} \mathrm{Da}\right)$ and functions to provide tonic signals that support homeostasis and suppress inflammation. ${ }^{18,19}$ Smaller forms of HA, termed HA fragments, are recognized by the cell as damage-associated molecular patterns. ${ }^{20}$ These fragments promote the expression of inflammatory cytokines in macrophages and drive cell cycle progression in smooth muscle cells. HA fragment interaction with RHAMM specifically is known to induce cytoskeletal changes and promote motility. ${ }^{21}$ By contrast, other glycosaminoglycans, such as chondroitin sulfate, have well-established roles in platelet function that depend on sulfation rather than molecular weight. ${ }^{22}$

In most somatic tissues, generation of HA fragments is the result of enzymatic degradation by hyaluronidase-2 (Hyal-2). Hyal-2 exists as a glycophosphatidylinositolanchored protein ${ }^{23,24}$ capable of cleaving $\mathrm{HA}$ at the plasma membrane. ${ }^{25-27}$ Studies of Hyal-2 knockout (KO) mice revealed increased levels of serum HA, craniofacial defects, cardiopulmonary dysfunction, impaired red cell

Supported by Programs of Excellence in Glycosciences grant HL107147 from the National Heart, Lung, and Blood Institute (C.A.d.1.M.).

Disclosures: None declared. 
survival, and macrothrombocytopenia. ${ }^{28,29}$ Data from our laboratory and others indicate that MKs and platelets contain HA, but little is known about its role in these cells. ${ }^{30,31}$ In addition, we found that both mouse and human MKs and platelets contain HYAL2 mRNA and protein with no evidence for HYAL1. ${ }^{31,32}$ Recently, it was reported that irradiated wild-type (WT) mice receiving transplants of Hyal-2 KO BM had reduced platelet levels, suggesting a role for intrinsic HA depolymerization by MKs in thrombopoiesis. ${ }^{33}$

We investigated the role of HYAL2 in MK maturation and platelet formation using Hyal-2 $\mathrm{KO}$ mice and by generating a CRISPR-Cas9 construct to disrupt Hyal-2 in the MEG-01 human megakaryoblast cell line. Analyses of BM from Hyal-2 KO mice revealed a significant accumulation of increased average-molecular-weight HA when compared with WT animals. Although the number of MKs in Hyal-2 KO BM was not statistically different, the percentage of apoptotic MKs was significantly increased. Furthermore, Hyal-2 KO MKs were found to be more immature and exhibited impaired proplatelet formation compared with WT MKs. DMS formation was disrupted in Hyal-2 KO MKs because of an inability to degrade intracellular HA. Importantly, proplatelet formation was partially rescued by addition of exogenous hyaluronidase in both murine BM MKs and human MEG01 MKs lacking Hyal-2. Taken together, our data establish a novel role for HA and Hyal-2 in thrombopoiesis and BM homeostasis.

\section{Materials and Methods}

Mice

All experiments were performed under an animal welfare protocol approved by the Lerner Research Institute's Institutional Animal Care and Use Committee. All mice were age matched at adult age, and controls and Hyal-2 $\mathrm{KO}$ outbred 129P1.CD1 Hyal2 ${ }^{\text {tml.1BFla }}$ mice $^{28}$ (or c57Bl/6 background where indicated) were used. Mice were housed and bred in specific pathogen-free microisolator cages and fed standard Teklad irradiated chow in the Association for Assessment and Accreditation of Laboratory Animal Care Internationalcertified Lerner Research Institute Biological Resource Unit.

\section{Cell Culture and in Vitro Proplatelet Formation}

The human MK MEG-01 cell line (ATCC, Manassas, VA) was maintained in RPMI 1640 medium supplemented with $10 \%$ fetal bovine serum, and $0.1 \mathrm{mg} / \mathrm{mL}$ of penicillinstreptomycin. Mouse BM was flushed from femurs and tibias with Tyrode buffer. The cells were then dissociated and cultured in Iscove's modified Dulbecco's medium supplemented with 5\% fetal bovine serum, $2 \mathrm{mmol} / \mathrm{L}$ L-glutamine, $50 \mathrm{U} / \mathrm{mL}$ of penicillin, $50 \mu \mathrm{g} / \mathrm{mL}$ of streptomycin, and 50 $\mathrm{ng} / \mathrm{mL}$ of thrombopoietin (TPO). After 3 days in culture, mature MKs were enriched by passing culture suspensions through a discontinuous density bovine serum albumin gradient. ${ }^{34}$ MKs recovered after density gradient filtration were then cultured for an additional day in the same medium. The percentage of MKs extending proplatelets was determined by using an inverted microscope (objective $40 \times / 0.55$; Leica Microsystems, Wetzlar, Germany), and approximately 300 cells were analyzed in each culture well.

\section{Biotinylation and Delivery of Streptomyces Hyaluronidase}

Streptomyces hyaluronidase (200 $\mu \mathrm{g}$; Sekigaku, Tokyo, Japan) was biotinylated according to the manufacturer's recommendation using EZ-link sulfo-NHS-LC biotinylation kit (Thermo Fisher Scientific Inc., Waltham, MA). Streptomyces hyaluronidase was delivered to cells by using the Chariot (Active Motif, Carlsbad, CA) protein delivery kit according to the manufacturer's specifications. Uptake of biotinylated enzyme with cells was detected by fluorescence using streptavidin-Alexa Fluor 568 (Life Technologies, Carlsbad, CA) or Western blot from cell lysates using a streptavidin-horseradish peroxidase conjugate.

\section{Mouse BM Histologic Analysis}

Mouse femurs were fixed for 48 hours in $10 \%$ neutral buffered formalin, and bones were then decalcified for 10 days in $12 \%$ EDTA (pH 8.0) at room temperature with constant rotation. EDTA was changed twice daily. Tissues were paraffin-embedded, sectioned, and stained with $\mathrm{H} \& \mathrm{E}$, HA-binding protein (HABP), or GP41/61. Staining was performed by the Cleveland Clinic Lerner Research Institute Histology Core Facility.

\section{HA Isolation and Sizing}

HA was purified from samples by centrifugation of isolated femurs and harvesting the expelled BM. BM was incubated with $0.5 \mathrm{mg} / \mathrm{mL}$ of proteinase- $\mathrm{K}$ in phosphate-buffered saline for 18 hours at $60^{\circ} \mathrm{C}$ followed by $50 \mathrm{U} / \mathrm{mL}$ of endonuclease from Serratia marcescens (Benzonase) for 1 hour at $37^{\circ} \mathrm{C}$. Digests were then dialyzed against $0.1 \mathrm{~mol} / \mathrm{L}$ $\mathrm{NaCl}$. Samples were applied to anion exchange spin columns (Thermo Fisher Scientific) and centrifuged for 5 minutes. Columns were washed twice with $0.1,0.2$, and 0.25 $\mathrm{mol} / \mathrm{L} \mathrm{NaCl}$ before $\mathrm{HA}$ was eluted with $0.8 \mathrm{~mol} / \mathrm{L} \mathrm{NaCl}$. Eluted samples that contained HA were dialyzed against water, concentrated, and analyzed using $0.5 \%$ agarose sizing gels as described previously. ${ }^{35}$ Stained bands in the gel were confirmed to be HA by demonstrating sensitivity to Streptomyces hyaluronidase $\left(2 \mathrm{U} / \mathrm{mL}\right.$ for one hour at $\left.37^{\circ} \mathrm{C}\right)$.

\section{TUNEL in Situ Apoptosis Analysis}

To determine the degree of apoptosis, terminal deoxynucleotidyl transferase-mediated dUTP nick-end labeling 
(TUNEL) staining was performed using an in situ cell death detection kit (Promega, Fitchburg, WI) following the manufacturer's protocol. Five femoral sections from each group were analyzed. MKs were detected by an antibody directed against von Willebrand factor (Abcam, Cambridge, UK), and Vectasheild mounting medium with DAPI was added. The number of apoptotic MKs (TUNEL and von Willebrand factor double-positive cells) was quantified in five randomly selected fields using a Leica upright microscope DM5500 B (Leica Microsystems).

\section{Immunohistochemistry}

BM-derived or MEG01 MKs were enriched over a bovine serum albumin gradient, fixed in $4 \%$ paraformaldehyde, and spun onto poly-L-lysine-coated coverslips at $250 \times g$ for 10 minutes. To observe MKs forming proplatelets, the cells were cultured on poly-L-lysine-coated coverslips. Cells were permeabilized by adding cold methanol for 5 minutes. Fixed specimens were washed in phosphate-buffered saline and blocked with $2 \%$ fetal bovine serum in Hanks' balanced salt solution for 1 hour. Cells were incubated with biotinyatedHABP (EMD Millipore, Billerica, MA) and an antibody against HYAL2 (Abcam), $\alpha$-tubulin (Sigma-Aldrich, St. Louis, MO), or GPIb $\beta$ (Emfret Analytics, Eibelstadt, Germany). After they were washed, the specimens were incubated with the appropriate Alexa Fluor secondary antibody for 45 minutes at room temperature and washed again. Then Vectasheild Mounting Medium with DAPI was added. Images were obtained using a Leica TCS SP5 II confocal/ multiphoton high-speed upright microscope (Leica Microsystems), HCX PL APO 63X/1.4NA oil immersion objective, Leica HyD system detector, Leica LAS AF software version 2.6 (Leica Microsystems), or Leica upright microscope DM5500 B (Leica Microsystems), HCX PLAN APO $\times 63 / 1.32 \mathrm{NA}$ oil immersion objective, QImaging Retiga cooled CCD camera, QCapture Suite software version 6.0 (QImaging, Surrey, BC, Canada). Images were generated using Fiji version 2.0 (http://fiji.sc) and ImageJ software version 1.47 (NIH, Bethesda, MD; http://imagej.nih.gov/ij). ${ }^{36}$

\section{Video Microscopy}

For real-time imaging, glass-bottom plates (MatTek Corporation, Ashland, MA) were coated with $100 \mu \mathrm{g} / \mathrm{mL}$ of poly-L-lysine (Sigma-Aldrich). Cells were incubated in the plates for 60 minutes to allow adhesion and then transferred to a humidified chamber at $37^{\circ} \mathrm{C}$ for video recording. Cells were examined on a Leica digital inverted microscope (Leica Microsystems) equipped with a $40 \times$ phase contrast long working distance condenser. Images were obtained using a Hamamatsu charge coupled device camera, and frames were captured at 10-minute intervals using the Leica application suite MultiTime software module version 4.4 (Leica Microsystems). Movies were generated using the Leica application suite (Leica Microsystems).

\section{Immunoblot Analysis}

Megakaryocytes were lyzed in $1 \%$ Nonidet P- $40,150 \mathrm{mmol} / \mathrm{L}$ $\mathrm{NaCl}$, and $50 \mathrm{mmol} / \mathrm{L}$ Tris(hydroxymethyl)aminomethane/ hydrochloric acid ( $\mathrm{pH} 7.4$ ), containing $1 \mathrm{mmol} / \mathrm{L}$ EGTA, $1 \mathrm{mmol} / \mathrm{L}$ sodium orthovanadate, and protease inhibitor cocktail (Sigma-Aldrich). SDS-PAGE buffer was added to lysates with 5\% $\beta$-mercaptoethanol. Proteins were resolved by SDS-PAGE and transferred onto nitrocellulose membrane. After being blocked overnight with $5 \%$ milk in phosphatebuffered saline, membranes were probed with rabbit antibodies directed against $\mathrm{Mpl}$ (Abcam), p38 mitogen-activated protein kinase (MAPK) or phospho-p38 MAPK (Cell Signaling Technology, Danvers, MA), and Hyal-2 (Abcam) and actin (Sigma-Aldrich), followed by secondary horseradish peroxidase-conjugated goat anti-rabbit $\mathrm{IgG}$ antibody (Thermo Fisher Scientific). ${ }^{37}$

\section{MK Ploidy}

BM cells were flushed with Hanks' balanced salt solution containing $0.38 \%$ sodium citrate, $1 \mathrm{mmol} / \mathrm{L}$ adenosine, $1 \mathrm{mmol} / \mathrm{L}$ theophylline, and 5\% fetal bovine serum (washing buffer), and erythrocytes were lyzed with $0.15 \mathrm{~mol} / \mathrm{L}$ ammonium chloride, $10 \mathrm{mmol} / \mathrm{L}$ potassium bicarbonate, and 0.1 $\mathrm{mmol} / \mathrm{L}$ disodium EDTA ( $\mathrm{pH}$ 7.4). BM cells were fixed in $70 \%$ ethanol, washed twice, and resuspended in washing buffer. Cells were incubated with phycoerythrin-conjugated rat anti-CD41 antibody or isotype control (eBioscience Inc., San Diego, CA). After being washed twice, cells were incubated with $0.5 \mathrm{mg} / \mathrm{mL}$ of RNase (Sigma-Aldrich), incubated with $50 \mu \mathrm{g} / \mathrm{mL}$ of propidium iodide, and analyzed by flow cytometry. Fifty thousand events per sample were acquired on a LSR II (BD Biosciences, San Jose, CA) and data analysis was performed with FlowJo software version 10.1 (Tree Star, Ashland, OR). ${ }^{38}$

\section{Electron Microscopy}

Cultured MKs were purified over a bovine serum albumin gradient and were fixed with $3.5 \%$ paraformaldehyde and $0.09 \%$ glutaraldehyde overnight. MK pellets were washed with phosphate-buffered saline, dehydrated with ethanol (30\% to $100 \%$ ), embedded with LR White medium, and polymerized at $50^{\circ} \mathrm{C}$ for 48 hours. Ultrathin sections cut with a diamond knife $(87 \mathrm{~nm})$ were mounted on formvar-coated nickel grids. Grids were washed with distilled water and stained with uranyl acetate and lead citrate, dried, and examined with a FEI Tecnai G2 Spirit BioTWIN Transmission Electron Microscope (FEI Company, Hillsboro, OR) at $60 \mathrm{kV}$.

\section{CRISPR-Cas9 Targeted DNA Deletion}

To generate a Hyal-2 megakaryoblast KO cell line, MEG-01 cells were seeded in 12-well plates at a density of 40,000 cells per well. After 24 hours, the cells were transfected 
with $0.5 \mu \mathrm{g}$ of pGS-gRNA-Cas9 with a puromycin resistance cassette containing the Hyal-2 genomic RNA targeting sequence (5'-ATACAGGCCTAGACGGTCG- $\left.{ }^{\prime}\right)$ (Genscript, Nanjing, China). After 3 days of selection in puromycin, cells were diluted to one cell per well into 96-well tissue culture plates that contained $200 \mu \mathrm{L}$ of media with puromycin. The level of Hyal-2 expression was analyzed for several clonal populations by Western blotting, and a single population with undetectable Hyal-2 levels was selected for study.

\section{TP0 and IL-6 Enzyme-Linked Immunosorbent Assay}

Mouse blood was collected by cardiac puncture, and serum was separated using Microtainer serum separator tubes (Becton-Dickinson, Franklin Lakes, NJ). TPO and IL-6 levels were quantified using mouse sandwich enzyme-linked immunosorbent assay kits (Raybiotech, Norcross, GA) according to the manufacturer's specifications. The sera were also measured for protein concentrations using the Bio-Rad Bradford assay system (Bio-Rad Laboratories, Hercules, CA). Both assay plates were read with the SpectraMax 340PC384 (Molecular Devices Corp., Sunnyvale, CA). The concentrations of TPO and IL-6 were then normalized to total protein in the serum.

\section{Real-Time Quantitative PCR}

RNA was extracted from BM with the RNAeasy mini kit (Qiagen GMbh, Hilden, Germany) according to the manufacturer's protocol. The RNA was eluted into $30 \mu \mathrm{L}$ of $\mathrm{H}_{2} \mathrm{O}$. After digestion of genomic DNA by DNase, reverse transcription using oligo-d(T) primers and M-MLV Reverse Transcriptase (Thermo Fisher Scientific) was completed in accordance with the manufacturer's instructions. The cDNA product was stored at $-20^{\circ} \mathrm{C}$ before quantitative PCR analysis. Validated primers with conjugated 6carboxyfluorescein (FAM) probes for Gatal, NFE2, EKLF, FLI, HAS1, HAS2, HAS3, HYAL1, TLR4, CD44, RHAMM, and 18S rRNA were purchased from Applied Biosystems (Invitrogen, Carlsbad, CA). The real-time PCR amplifications were performed in $25-\mu \mathrm{L}$ reaction volumes that contained TaqMan gene expression Master Mix, primers and fluorogenic probes (Invitrogen), and cDNA. All reactions were performed with four replicate reactions using a Bio-Rad C1000 Touch Thermal Cycler with attached CFX96 Real-Time System (Bio-Rad Laboratories). The real-time PCR reaction conditions were $50^{\circ} \mathrm{C}$ for 2 minutes and $95^{\circ} \mathrm{C}$ for 10 minutes, followed by 50 cycles of $95^{\circ} \mathrm{C}$ for 15 seconds and $60^{\circ} \mathrm{C}$ for 60 seconds. Real-time detection data were analyzed using Bio-Rad CFX Manager software version 2.1 (Bio-Rad Laboratories). Changes in gene expression were calculated using the Livak $(\Delta \Delta \mathrm{CT})$ method. ${ }^{39}$

\section{Statistical Analysis}

All experiments were performed at least in triplicate, and data are represented as means \pm SEM. Data were analyzed with the $t$-test using Prism software version 6.0 (GraphPad Software Inc., La Jolla, CA). Differences were considered significant at $P<0.05$.

\section{Results}

\section{HA Accumulates in the BM of Hyal-2 KO Mice}

A previous report found that Hyal-2 deficiency in mice causes multiple defects, including severe thrombocytopenia, ${ }^{28}$ with a approximately $70 \%$ reduction in circulating platelets, a finding we confirmed in 2 different genetic backgrounds $\left(\mathrm{WT}=953 \pm 187 \times 10^{3}\right.$ cells $/ \mu \mathrm{L}$ compared with $245 \pm 113$ $\times 10^{3}$ cells $/ \mu \mathrm{L}$ for Hyal-2 KO mice, $n=12$ for each). Interestingly, platelet half-life was found to be normal in Hyal2 KO mice (data not shown). To better understand how the loss of Hyal-2 leads to reductions in platelet levels, we examined the BM of Hyal-2 KO mice. Gross BM morphologic features appeared normal by hematoxylin and eosin staining when compared with WT mice (Figure 1A). Megakaryopoiesis was investigated by histochemical staining for a marker of MKs: CD41/61. Whereas the CD41/61 staining appeared to be more intense in KO MKs, Hyal-2 KO animals had only a modest reduction in the number of MKs per visual field when compared with WT littermates (Figure 1B). We next determined the localization and amount of HA within KO BM by HABP staining. Most HA detected in the BM was diffusely distributed in the extracellular space and lining BM sinusoids (Figure 1A). As expected, Hyal-2 KO mice had significantly increased levels of HA within the BM. Although most HA is pericellular, specific cells (including MKs) appeared to contain intracellular HA (Figure 1A). Next, we evaluated the size of HA by purifying BM glycosaminoglycans and analyzing size distribution by agarose gel electrophoresis. High levels of HA were observed in the samples from Hyal-2 KO mice, as seen by the increase in dark-stained material throughout all polydisperse molecular weights (Figure 1C). These data are consistent with our histochemical observations of an accumulation of HA within the BM. In addition, our analyses revealed a significant increase in the amount of highmolecular-weight HA in Hyal-2 marrow (Figure 1D). We further analyzed the BM for relative expression levels of the three HAS enzymes, Hyal-1, and several HA receptors and found no statistical change in expression (Supplemental Figure S1). On the basis of these findings, we concluded that the increase in HA was due to the loss of Hyal-2, which affects the maintenance of extracellular HA in the BM.

\section{Megakaryocyte Apoptosis Is Increased in Hyal-2 KO BM}

The observation that MKs are present at levels close to WT in Hyal-2 KO animals suggests that the cause of thrombocytopenia may a defect intrinsic to MKs. Therefore, we analyzed circulating levels of TPO (Figure 2A) and IL-6 (Figure 2B), two thrombopoietic cytokines known to stimulate MK proliferation, survival, maturation, and platelet 


\section{A}

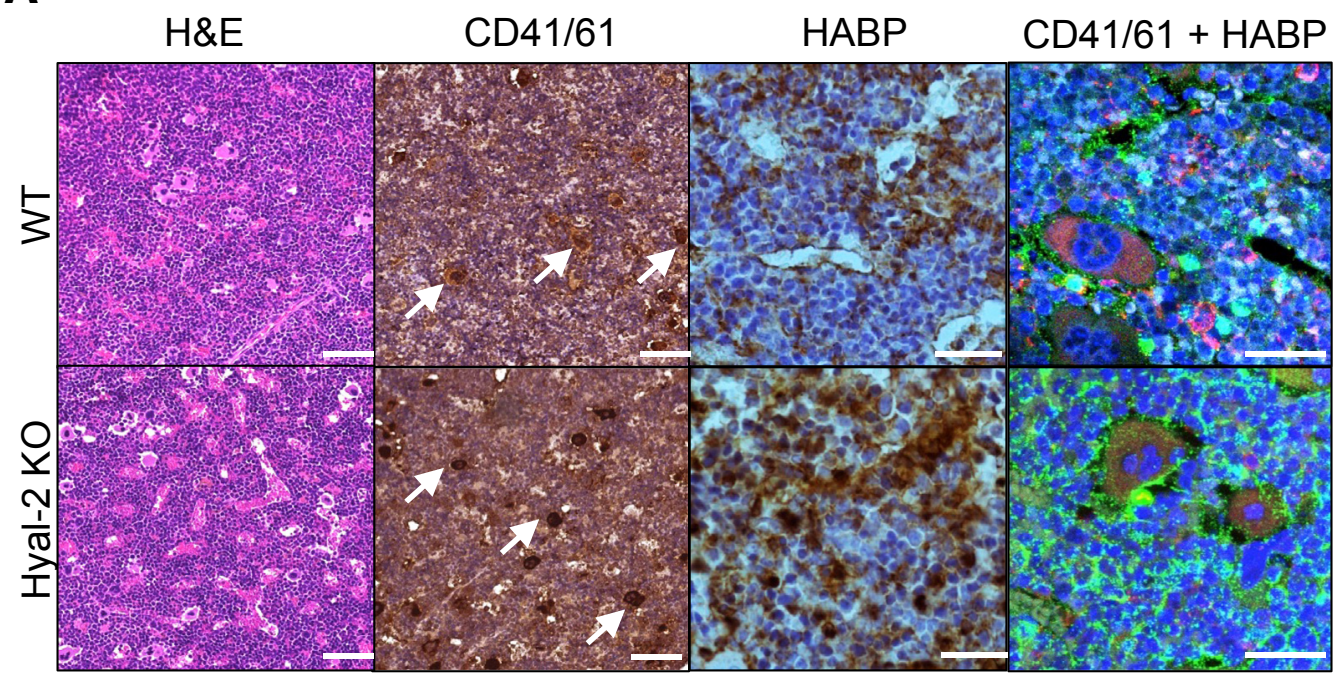

B

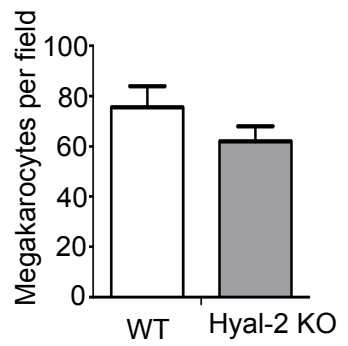

C

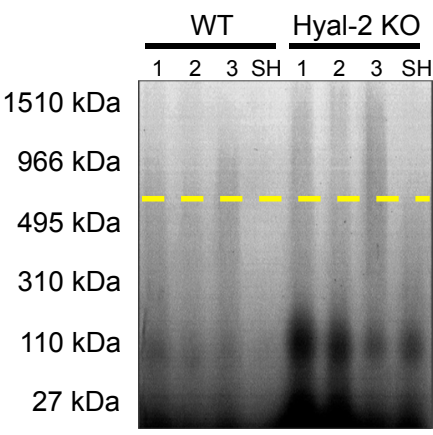

D

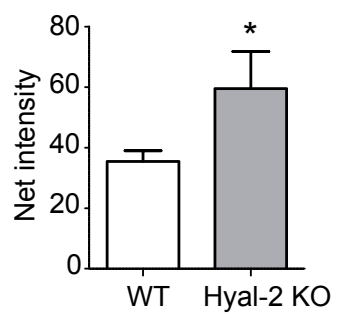

Figure 1 Hyaluronan accumulates in the bone marrow (BM) of hyaluronidase-2 (Hyal-2) knockout (KO) mice. A: Hematoxylin and eosin (H\&E), CD41/61 specific antibody, and hyaluronan-binding protein (HABP) histochemical and fluorescence histochemical (HA, green; CD41/61, red) staining of wild-type (WT) and Hyal-2 femur BM sections. Arrows indicate CD41/61 megakaryocytes (MKs). B: Quantification of morphologically recognizable CD41/61 $1^{+}$WT and Hyal-2 BM MKs. C: Representative HA sizing gel of femoral bone marrow isolates purified from four WT and Hyal-2 mice. Each lane corresponds to two femurs from one mouse. Predigestion of mouse bone marrow isolates with Streptomyces hyaluronidase (SH) is used as a specificity control for one mouse isolate. HA can be observed as a dark material that is removed by specific hyaluronidase digestion. D: Densitometry quantification of high-molecular-weight HA is indicated above the dashed yellow line in C. Data are expressed as means \pm SEM (A). $n=6$ mice per group (A); $n=8$ mice analyzed in each group (B and $\mathbf{C})$. ${ }^{*} P<0.05$. Scale bar $=25 \mu \mathrm{m}$.

production. ${ }^{40-42}$ Neither serum TPO nor IL-6 levels differed between WT and KO mice, suggesting that the platelet and MK volume in KO animals was likely sufficient to regulate these factors. In addition, we found no change in steady-state IL-6 receptor levels by Western blot in purified MKs lacking Hyal-2 compared with controls. Because TPO and IL- 6 were unchanged, we next considered whether loss of Hyal-2 might attenuate MK survival. We examined the BM in situ for apoptotic MKs by using the combination of von Willebrand factor staining and TUNEL (Figure 2C). Analysis revealed that the relative percentage of mature apoptotic MKs was increased in the femurs of $\mathrm{KO}$ animals $(12 \% \pm 2.2 \%)$ compared with WT controls $(5 \% \pm 1.3 \%)$ (Figure 2D). Induction of apoptosis was further evaluated by Western blot analysis of caspase-9 activation and Bcl-xL. These findings confirmed that proapoptotic activation of caspase- 9 was increased in purified Hyal-2KO MKs, whereas antiapoptotic Bcl-xL was decreased (Figure 2E).
TPO-mediated megakaryopoiesis is regulated through interaction of the cytokine with its receptor, c-MPL. ${ }^{43-47}$ On binding and initiating downstream signals, both TPO and c-MPL are internalized and degraded, resulting in a ligand-induced negative feedback loop. ${ }^{46}$ Because both HA and Hyal-2 form complexes with cell surface receptors, ${ }^{27,48,49}$ we evaluated whether the loss of Hyal-2 might affect c-Mpl expression. For these experiments, we used both murine and human MKs. We first confirmed that the human MEG01 MK cell line contains both Hyal-2 and HA and then subsequently disrupted Hyal-2 using a CRISPR-Cas9 targeted deletion (Supplemental Figure S2). We found no change in steady-state c-Mpl levels by Western blot in either BM-derived MKs or MEG01 MKs lacking Hyal-2 compared with controls (Figure 2F).

Increasing evidence indicates that $\mathrm{HA}$ is capable of signaling through several receptors, including TLRs and CD44 (both of which are expressed in MKs). In addition, HA regulates cell behavior in a number of cell types, including 
A

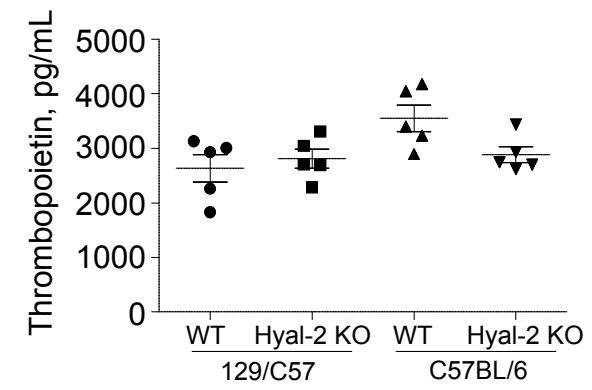

C

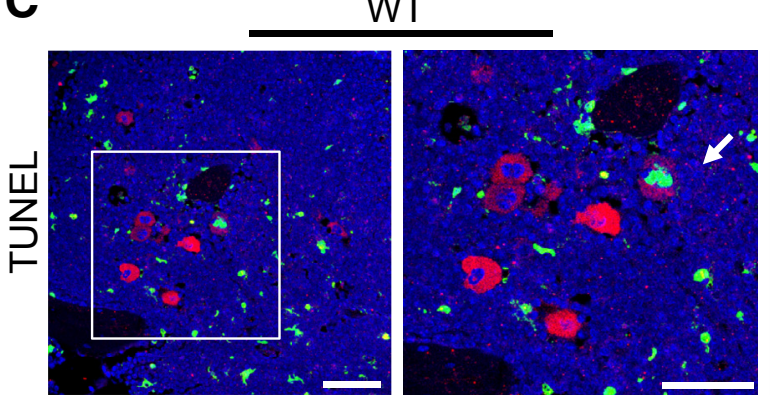

D

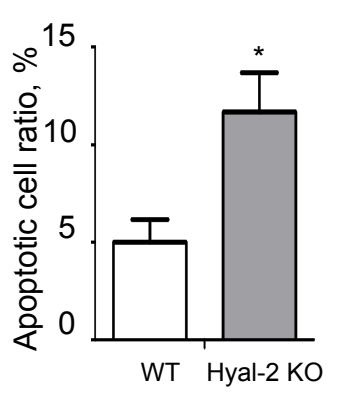

B

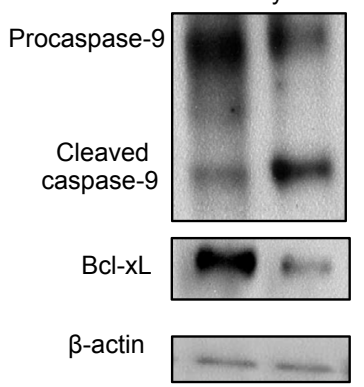

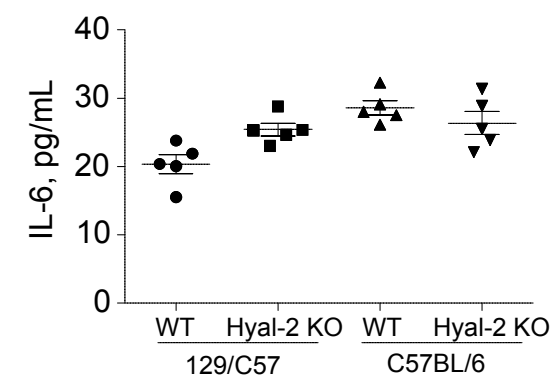

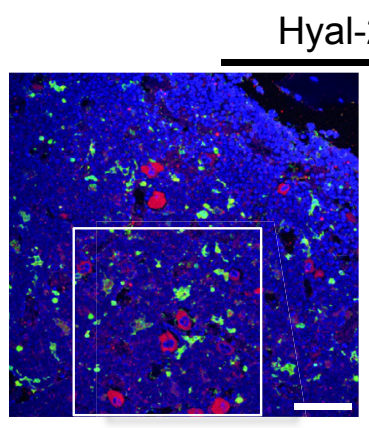

$\mathbf{F}$

BM

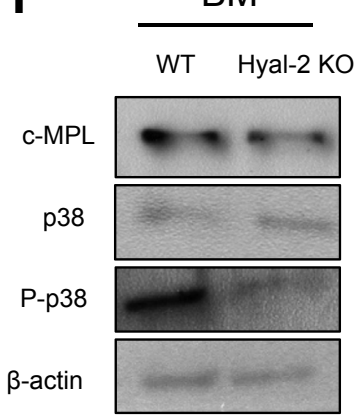

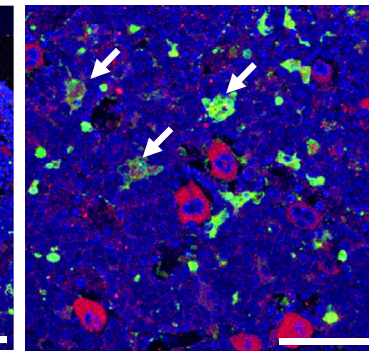

MEG01

Figure 2 Reduced megakaryocyte (MK) survival in hyaluronidase-2 (Hyal-2) knockout (K0) mice. Serum thrombopoietin (TP0) (A) and IL-6 (B) levels in wild-type (WT) and Hyal-2 KO mice. C: Representative images of terminal deoxynucleotidyl transferase-mediated dUTP nick-end labeling (TUNEL)-positive (green) and von Willebrand factor-positive (red) bone marrow (BM) cells. Arrows indicate TUNEL-positive (costained) MKs. Areas within boxes are shown at higher magnification in adjacent panels. D: TUNEL-positive cell ratios of morphologically recognizable MKs in the BM. E: Total protein (10 $\mu \mathrm{g})$ samples from CD41 ${ }^{+}$purified MKs from murine BM were analyzed by immunoblots for caspase- 9 and Bcl-xL. F: Total protein $(10 \mu \mathrm{g})$ samples from murine and human MEG01 MKs were analyzed by immunoblots for c-MPL, p38, phospho-p38 (P-p38), and $\beta$-actin. Immunoblot analyses were performed on at least four mice per group. Data are expressed as means $\pm \operatorname{SEM}(\mathbf{A}$ and $\mathbf{B}) . n=5$ per group $(\mathbf{A}, \mathbf{B}$, and $\mathbf{D}) ; n=$ at least 4 per group $(\mathbf{F})$. ${ }^{*} P<0.05$. Scale bar $=25 \mu \mathrm{m}$. Ctrl, control.

hematopoietic progenitors. ${ }^{17,18,31,50,51}$ We therefore considered whether the accumulation of HA might affect downstream signal transduction in MKs. Consistent with our hypothesis, we found a significant decrease in the phosphorylation of p38 MAPK (p38) in both BM-derived or human MEG01 MKs lacking Hyal-2 (Figure 2F) compared with controls. However, we found no change in ERK1/2 activation. Taken together, HA appears to have a role in the regulation of MK survival, likely through a p38-mediated mechanism.

\section{Megakaryocyte Maturation Is Impaired in Hyal-2 KO BM}

Two key features of MK maturation are polyploidization and an expansion of cytoplasmic mass (as the cell increases in volume, MKs reach sizes approximately 50 to $100 \mu \mathrm{m}$ in diameter and reported ploidy distributions up to $128 \mathrm{~N}$ ). As the MK matures, the cytoplasm and platelet organelles expand, and the DMS is amplified in preparation for proplatelet biogenesis. ${ }^{2}$ Therefore, we determined whether altered HA turnover affects MK maturation by examining the ploidy of MKs from freshly isolated BM. The mean number of $\mathrm{CD} 41^{+}$MKs were similar among mice (Figure 3A), consistent with our observations from femoral sections (Figure 1B). However, although there was no significant change in mean ploidy (data not shown), the ploidy distribution of Hyal-2 KO MKs was significantly different when compared with control (Figure 3B). Hyal-2 KO MKs were less mature with an increase in $4 \mathrm{~N}$ populations, 


\section{A}

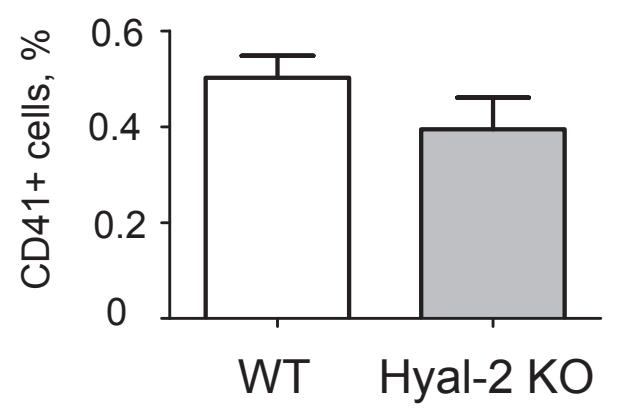

B

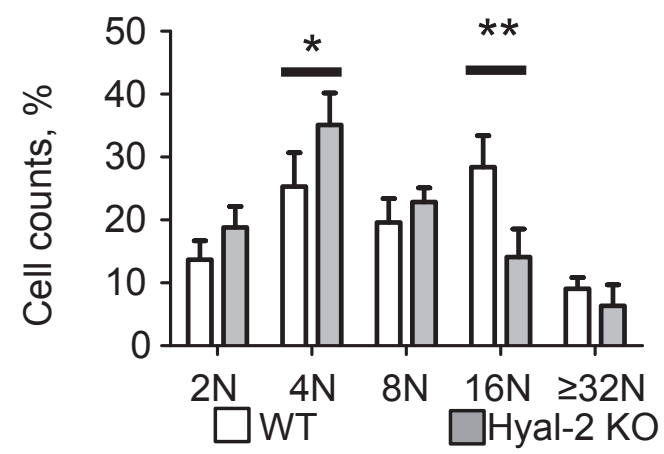

C

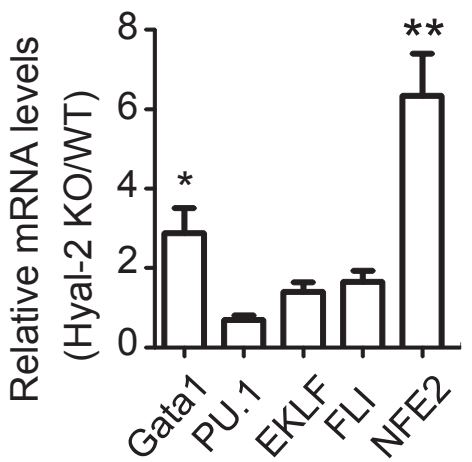

Figure 3 Impaired maturation of hyaluronidase-2 (Hyal-2) knockout (K0) megakaryocytes (MKs). A: Flow cytometric analyses of $\mathrm{CD} 41^{+}$bone marrow (MB) MK frequency. B: Ploidy distribution of wild-type (WT) and Hyal-2 BM MKs. C: Real-time quantitative PCR analyses of myeloid transcription factors in Hyal-2 KO versus WT BM normalized to $18 \mathrm{~S}$ rRNA. Data are expressed as means \pm SEM. $n=5$ per group $(\mathbf{A}-\mathbf{C}) .{ }^{*} P<0.05,{ }^{*} P<0.01$.

whereas $16 \mathrm{~N}$ and $32 \mathrm{~N}$ represented only $20.4 \% \pm 7.8 \%$ of total BM MKs compared with $38.6 \% \pm 6.8 \%$ in WT mice. These data indicate a disruption in normal MK maturation.

Thrombopoiesis within the $\mathrm{BM}$ is a tightly regulated process in which lineage-restricting transcription factors direct the maturation of a progenitor cell toward a specific fate. ${ }^{53}$ Because previous studies indicated an increase in immature erythroid cells in Hyal-2 $\mathrm{KO}$ animals, ${ }^{28,33}$ we next investigated whether myeloid progenitor cell maturation might also be disrupted in these animals. Both erythrocytes and MKs are derived from a common bipotential progenitor, and we therefore analyzed a set of lineage-restricting transcription factors with major roles in thrombopoiesis in total BM isolates. These data revealed that GATA1, the principle erythroid-megakaryocyte lineage-determining transcription factor, ${ }^{54}$ and NFE2, a key regulator of MK terminal differentiation, ${ }^{55}$ were significantly increased in Hyal-2 $\mathrm{KO}$ BM compared with control (Figure 3C). Collectively, these data indicate that disruption of HA homeostasis within the BM leads to attenuated MK maturation and a compensatory increase in MK maturation transcription factors.

\section{Proplatelet Formation Is Aberrant in Hyal-2 KO MKs}

To directly determine the ability of Hyal-2 KO MKs to produce proplatelets, we used an in vitro $\mathrm{MK}$ differentiation system and observed the morphologic features of MKs forming proplatelets in real-time. Megakaryocytes from WT BM underwent highly dynamic morphologic changes and extended irregular membrane processes before the formation of pseudopodia (Figure 4A and Supplemental Video S1). As the cell expands, it elongates proplatelets from the peripheral edge of the membrane until the entire cytoplasm is elaborated into a network of interconnected proplatelets. In contrast, MKs from Hyal-2 KO BM appear to begin proplatelet formation in a similar fashion, including the formation of pseudopodia. However, their cytoplasm twists and expands, appearing almost folded with unusual ring-like structures visible along the perimeter of the cell (Figure 4B and Supplemental Video S2). Strikingly, the inability of an MK to remodel HA in the absence of Hyal-2 impairs proplatelet formation.

\section{HA and Hyal-2 Are Contained within Proplatelet Extensions}

Because our microscopic analysis indicated that the proplatelet formation was severely impaired by the loss of Hyal-2, we further investigated the involvement of HA in WT MKs and a subset of Hyal-2 KO MKs still capable of forming proplatelets. MKs derived from WT BM form numerous long, branched proplatelet extensions with platelet-sized bulges (Figure 5A). Conversely, proplatelets from Hyal-2 KO MKs appeared shorter, appeared less complex, and had unusual looped structures (Figure 5B). We hypothesized that the disrupted morphologic features may result from an inability to remodel intracellular HA; therefore, we investigated the localization of HA and Hyal-2 within proplatelet-forming MKs. Similar to $\alpha$-tubulin, HA was detected throughout the cell body and the proplatelet extensions of WT MKs and appeared distributed as a weblike network. Importantly, the localization of Hyal-2 was close to HA but somewhat more restricted within the cell body and also along the length of proplatelet extensions (Figure 5C). By contrast, the HA within Hyal-2 KO MKs appeared more diffuse and overall less structured, with regions of accumulation evident within nodes along 

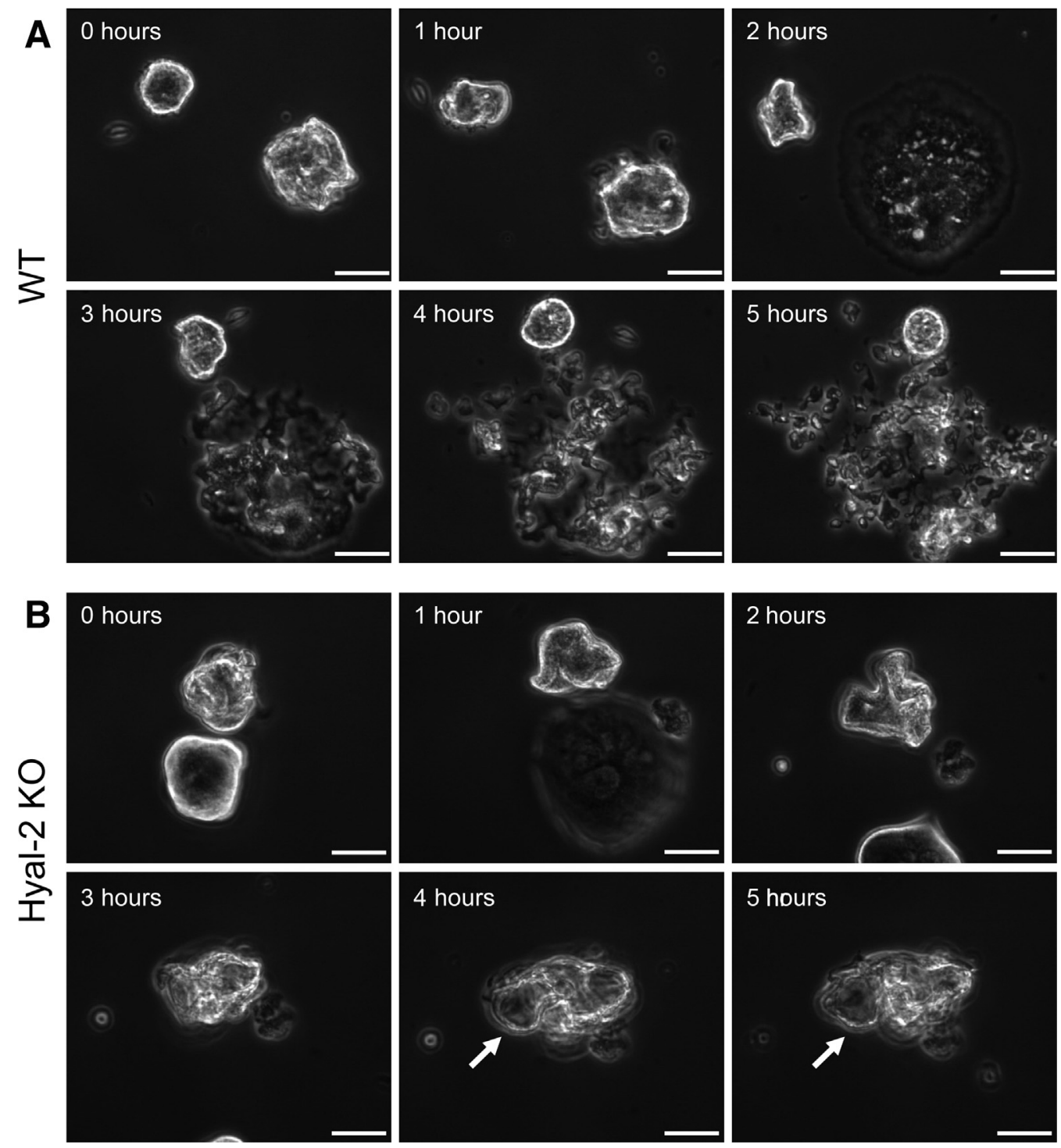

Figure 4 Proplatelet formation is abnormal in hyaluronidase-2 (Hyal-2) knockout (KO) megakaryocytes (MKs). Time-lapse images from video-enhanced phase-contrast microscopy showing either wild-type (WT) (A) or Hyal-2 (B) bone marrow-derived MKs forming proplatelets. Arrows indicate unusual proplatelet structures. Scale bar $=50 \mu \mathrm{m}$. Videos are provided as Supplemental Videos S1 and S2.

proplatelet loops (Figure 5D). These data reveal that both HA and Hyal-2 are localized at the site of proplatelet formation and disruption of HA depolymerization leads to abnormal proplatelet morphologic features.

\section{The DMS of Hyal-2 KO MKs Is Substantially Disrupted}

The significant difference in platelet counts and abnormal morphologic feature of proplatelet-forming MKs prompted us to examine the ultrastructure of Hyal-2 KO BM MKs. Control WT MKs formed an elaborate DMS that contained membrane tubules organized into several rows of territories around the circumference of the cell (Figure 6A). Strikingly, Hyal-2 KO MKs had a poorly developed DMS, which appeared dilated with increased cytoplasmic space. This revealed that the membrane network, which divides the MK cytoplasm into fields where individual platelets are formed, was significantly altered in Hyal-2 KO MKs (Figure 6B) when compared with control. We further investigated the molecular basis underlying the DMS disruption by immunostaining for GPIb $\beta$, a marker of the DMS, and observed MKs by confocal fluorescence microscopy. Consistent with our transmission electron microscopy images (Figure 6A), the DMS appeared as a complex network in WT MKs, extending throughout the cytoplasm to the plasma membrane, with HA fully dispersed throughout the cell (Figure 6C). By contrast, GPIb $\beta$ in Hyal-2 KO MKs appeared significantly less complex, with the most intense staining adjacent to the plasma membrane (Figure 6D). Thus, although Hyal-2 KO MKs were capable of forming proplatelets, cytoplasmic morphogenesis was disrupted with abnormal DMS formation of platelet territories. 

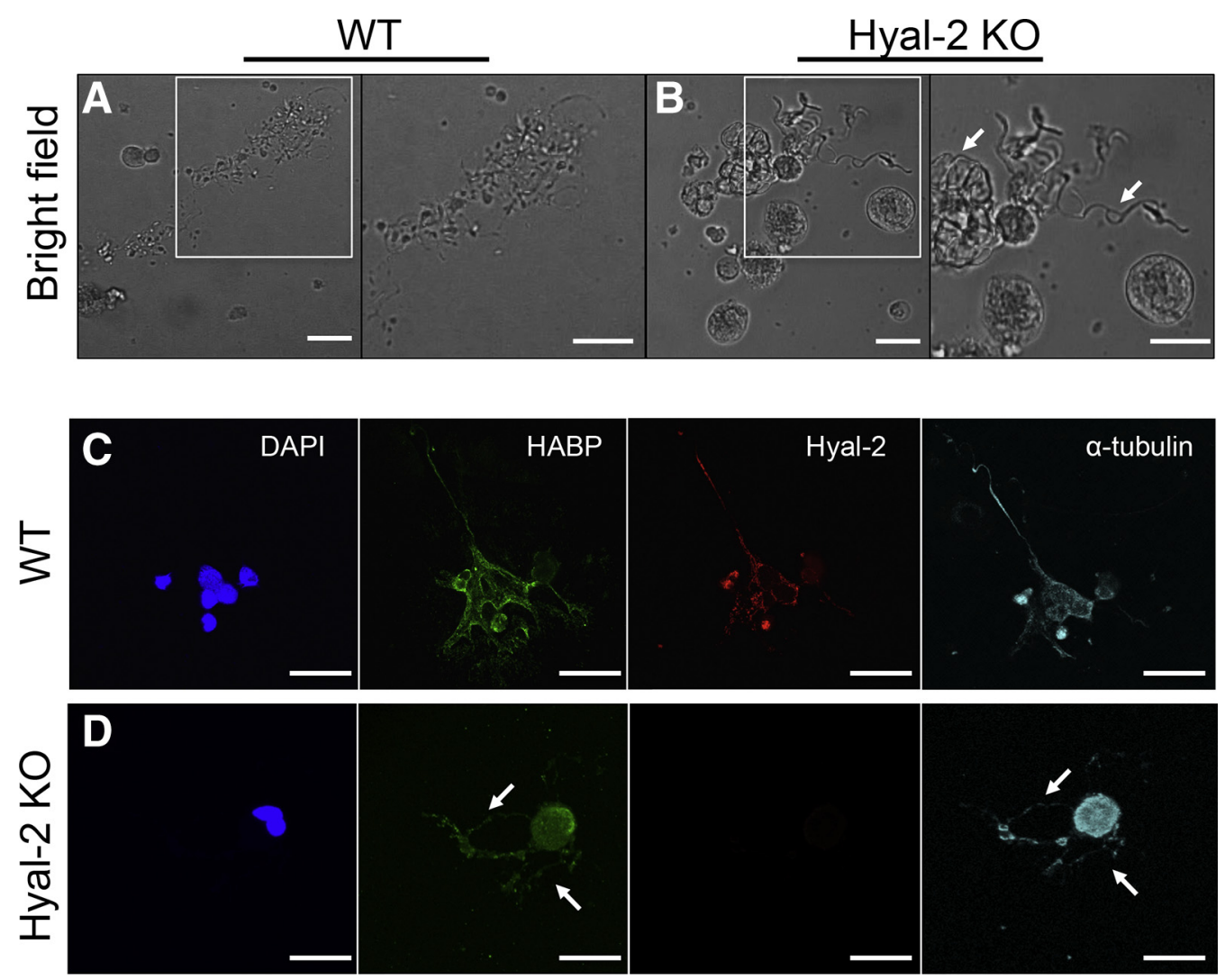

Figure 5 Proplatelet formation is disrupted by impaired hyaluronan (HA) degradation. Representative light microscopy images of bone marrow (BM)derived wild-type (WT) (A) and hyaluronidase-2 (Hyal-2) (B) proplatelet-forming megakaryocytes (MKs) in vitro. Areas within boxes in A and B are shown at higher magnification in adjacent panels. Representative DAPI, HA-binding protein (HABP), Hyal-2, and $\alpha$-tubulin immunofluorescence images of WT (C) and Hyal-2 (D) BM MKs. Arrows indicate abnormal looped proplatelet structures in $\mathbf{B}$ and $\mathbf{D}$. Scale bar $=50 \mu \mathrm{m}$. Original magnification: $\times 20(\mathbf{A}$ and $\mathbf{B}$, right panels); $\times 34$ (A and B, left panels).

\section{HA Depolymerization Is an Important Step in Proplatelet Formation}

We hypothesized that the disruption of proplatelet formation might arise from an increase in HA, caused by the absence of Hyal-2, which altered proplatelet field organization in MKs. To test this hypothesis, we delivered exogenous hyaluronidase to both murine and human MKs in culture. Strikingly, for cells that lacked Hyal-2, enzyme supplementation recovered the numbers of proplatelet-forming MKs in murine BM-derived MKs (Figure 7A) and in human MEG01 MKs (Figure 7B) close to normal levels. Although we were able to confirm uptake of the enzyme (Supplemental Figure S3), the addition of exogenous hyaluronidase did not appear to change the abnormal morphologic features of proplatelet-forming MKs lacking Hyal-2. Taken together, Hyal-2 functions to degrade intracellular $\mathrm{HA}$ in cultured MKs, thereby promoting proplatelet formation (Figure 7C).

\section{Discussion}

The present study provides new insight into BM homeostasis and mechanisms that lead to thrombocytopenia through examination of various aspects of megakaryopoiesis in situ and in vitro. We found that the depolymerization of HA contained within the cytoplasm of MKs is an important element of proplatelet formation. Our results indicate that Hyal-2-dependent HA degradation has previously unrecognized roles in megakaryocyte maturation and thrombopoiesis. Although there are several members of the hyaluronidase family present in vertebrates, only systemic KO of Hyal-2 leads to thrombocytopenia. This is consistent with our observation that Hyal-2 is the only hyaluronidase expressed by platelets and MKs. ${ }^{31}$ Histochemical analyses of BM from Hyal-2 KO mice reveal a significant increase in highmolecular-mass HA in the extracellular space and surrounding BM sinusoids (Figure 1A). Previous studies have found that the interaction of progenitor cells and pericellular HA is capable of regulating downstream intracellular pathways governing proliferation through CD44 and other receptors. ${ }^{50,51,56}$ However, MKs are distinguished from other progenitor cell types by a number of features, including the intracellular localization of HA and cognate receptors. ${ }^{30,57}$ Despite pronounced thrombocytopenia in Hyal-2 $\mathrm{KO}$ animals, we found a statistically insignificant decrease in the number of MKs present within the BM when compared with controls (Figure 1B). 


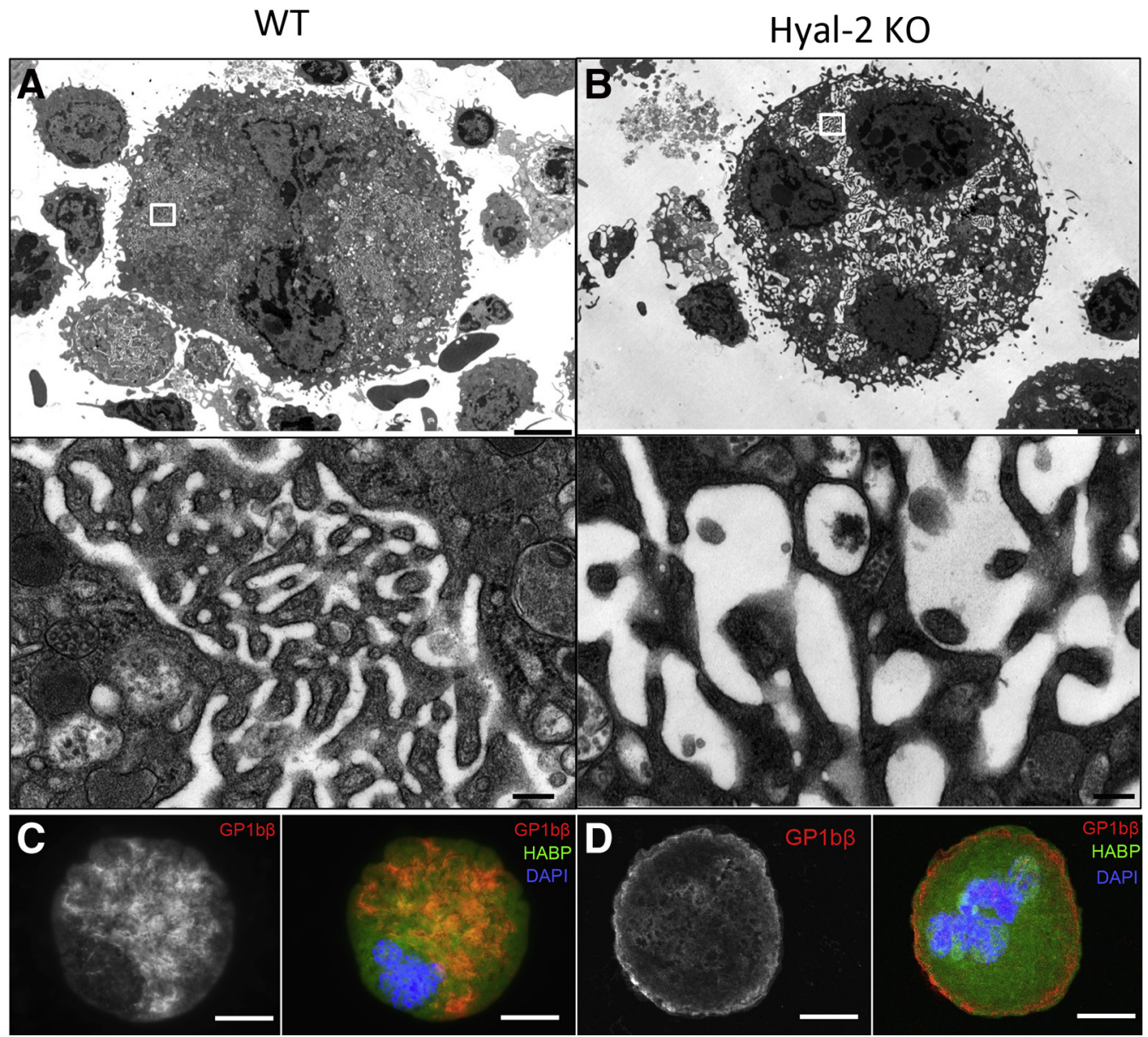

Figure 6 The demarcation membrane system of megakaryocytes (MKs) lacking hyaluronidase-2 (Hyal-2) is malformed. Transmission electron microscopy analysis of wild-type (WT) (A) and Hyal-2 knockout (KO) (B) bone marrow-derived MKs. Areas within boxes in $\mathbf{A}$ and $\mathbf{B}$ are shown at higher magnification in the respective panels below. Representative immunofluorescence images of glycoprotein $\operatorname{Ib} \beta$ (GPIb $\beta$ ) (red) as a demarcation membrane system marker in WT (C) and Hyal-2 KO (D) MKs. Overlay with HA-binding protein (HABP) (green) and DAPI (blue) is shown in adjacent panels. Scale bars: $5 \mu \mathrm{m}$ (A and $\mathbf{B}$, top panels); $200 \mathrm{~nm}$ (A and B, bottom panels); $25 \mu \mathrm{m}$ (C and D). Original magnification: $\times 5385$ (A and B, top panels); $\times 91,568$ (A and B, bottom panels).

Our present data also reveal that maturation (Figure 3B) and survival (Figure 2, C-E) of MKs in Hyal-2 KO animals are severely impaired. Although compartmentalized cell death is a temporal aspect of proplatelet-forming MKs, premature apoptosis can directly lead to thrombocytopenia, for example, as a result of radiotherapy. ${ }^{58}$ Interestingly, the maturation profile of MKs from Hyal-2 BM appeared significantly more immature relative to control (Figure 3B), and analysis of transcription factors that regulate $\mathrm{MK}$ and platelet biogenesis reveal increases in KO BM (Figure 3C). Among these, GATA-1 and NF-E2 are believed to function in parallel fashion to promote thrombopoiesis. GATA-1 is initially required to commit a common bipotential progenitor to the MK lineage, but it also regulates all stages of MK development. ${ }^{54}$ However, NF-E2 induces MK maturation and regulates several genes crucial to proplatelet formation. ${ }^{7,55,59}$ Our data suggest that the increased levels of GATA-1 and NF-E2 in Hyal-2 KO BM may be a compensatory mechanism, driving the common myeloid progenitor toward enhanced MK commitment and increasing the number of MK progenitors. High levels of these transcription factors could possibly affect lymphoid progenitor lineage programming as well. ${ }^{60}$

Multiple reports in the past several decades have elucidated many of the mechanistic events underlying the formation of proplatelets and the subsequent release of platelet-sized particles, with considerable emphasis on the important role of cytoskeletal dynamics. Our data reveal that the functional interaction between HA and Hyal-2 has a critical role in platelet biogenesis within the cell. Hyal-2 and $\mathrm{HA}$ are localized along the lengths of proplatelet extensions in control MKs (Figure 5C), and the loss of Hyal-2 leads to impaired proplatelet formation in both murine and human MKs. Although genetic KO can lead to off-target effects, importantly, deficient proplatelet formation observed in this model is rescued by the addition of exogenous hyaluronidase (Figure 7A).

In addition, this report also indicates that disruption of HA remodeling has unexpected consequences on DMS formation (Figure 6). BM-derived Hyal-2 KO MKs have a strikingly abnormal DMS, appearing as a swollen and dilated membrane network reminiscent of the DMS 
A

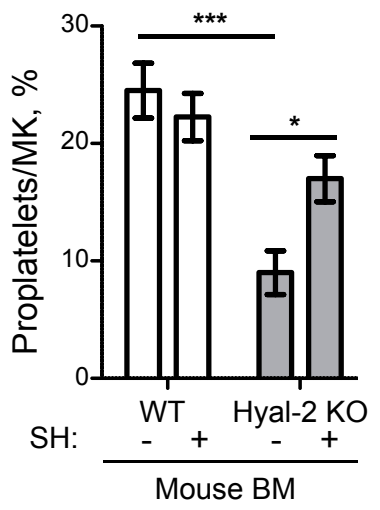

C

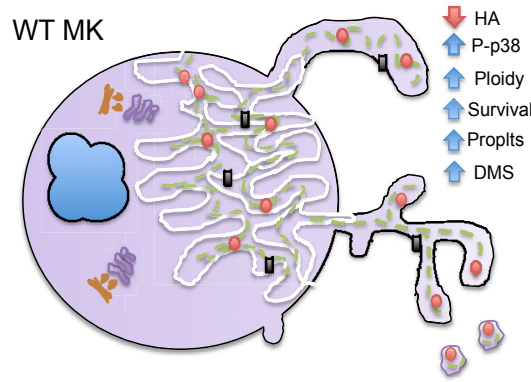

B

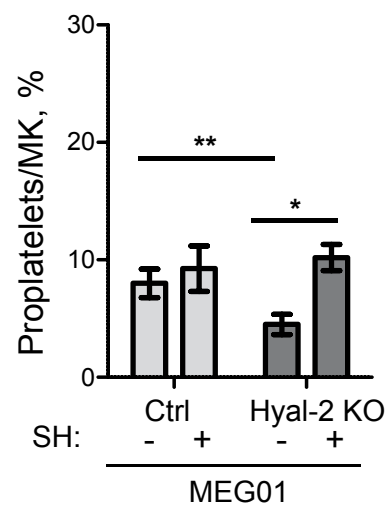

D

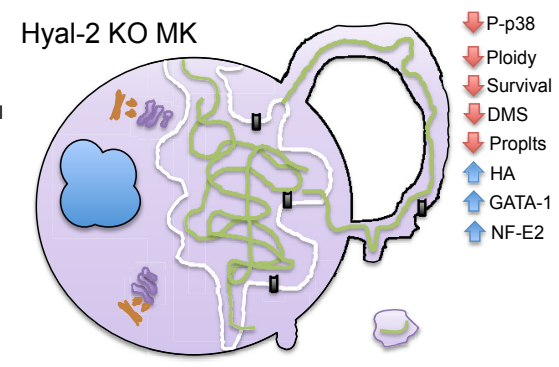

DMS

Polyploid Nuclei
Figure 7 Hyaluronan (HA) degradation is a key component of proplatelet formation. Bone marrow (BM)-derived or mature MEG01 megakaryocytes (MKs) were incubated with Chariot reagent alone or with $5 \mu \mathrm{g}$ of Streptomyces hyaluronidase $(\mathrm{SH})$. Quantification of proplateletforming MKs: Mouse BM-derived MKs from wildtype (WT) and hyaluronidase-2 (Hyal-2) knockout (KO) (A) and MEG01 proplatelet-forming MKs (B). C: Model of proplatelet biogenesis suggested by these experiments. During maturation, HA synthase enzymes within the demarcation membrane system (DMS) produce HA as MKs increase in size. Hyal-2 is derived from the Golgi and depolymerizes $H A$, supporting DMS formation and development of proplatelet fields. D: In the absence of Hyal-2, HA accumulates within the DMS, impairing MK maturation and subsequent proplatelet formation. Data are expressed as means \pm SEM (A and $\mathbf{B})$. $n=8 \mathrm{WT}$ and $12 \mathrm{Hyal}-2 \mathrm{KO}$ mice $(\mathbf{A}) ; n=12(\mathbf{B})$. ${ }^{*} P<0.05,{ }^{* * P}<0.01$, and ${ }^{* * * P}<0.001$. Ctrl, control; ER, endoplasmic reticulum; P-p38, phospho-p38. abnormalities observed in a glycoprotein $\mathrm{Ib} \beta$-deficient murine model of Bernard-Soulier syndrome. ${ }^{61}$ As MKs mature, they increase in size and synthesize the membrane network that gives rise to the DMS. Our data suggest that HA and Hyal-2 are involved in this process, and we propose that HA biosynthesis supports early MK development and that as MKs mature intracellular HA is processed by Hyal-2, supporting the formation of a compact DMS throughout the MK cytoplasm. In the absence of Hyal-2, large HA polymers are unable to be processed to smaller sizes and contribute to the swollen compartmentalized DMS observed in Hyal-2 KO MKs (Figure 6 and Figure 7C). Indeed, recent evidence indicates that DMS biogenesis is initiated at the plasma membrane in glycoprotein $\mathrm{Ib} \beta^{+}$pre-DMS clusters and the newly synthesized membrane becomes invaginated, thereby initiating formation of the DMS. ${ }^{5}$ Expansion of the DMS requires vesicular membrane delivery from numerous Golgi complexes within the MK, and it seems plausible that the HA biosynthetic enzymes and Hyal-2 are contained within Golgi vesicles and are targeted to the DMS. An additional noteworthy finding of our study is that although the addition of exogenous hyaluronidase led to a recovery in the number of proplatelets released from MKs, the treatment did not rescue the abnormal morphologic features seen in Hyal-2deficient MKs, suggesting that Hyal-2 interactions with other proteins may contribute as well (Figure 4B and Figure 5, C and
D). Therefore, the addition of hyaluronidase cannot correct the abnormal DMS architecture once the DMS is formed. The specific cellular mechanism by which HA depolymerization supports DMS biogenesis requires further study.

Our data indicate that despite what appear to be a severe thrombocytopenia, serum TPO levels are not increased (Figure 2A). Although Hyal-2 KO MKs release fewer proplatelets per $\mathrm{MK}$ in vitro, we observed that Hyal-2 $\mathrm{KO}$ MKs consistently produced proplatelets at an earlier maturation stage than WT MKs (Figures 4 and 5). In light of our findings that transcription factors driving the myeloid lineage toward $\mathrm{MK}$ commitment are significantly elevated (Figure $3 \mathrm{C}$ ), it is possible that the rates of $\mathrm{MK}$ progenitor proliferation and platelet production are increased to compensate for increased apoptosis in Hyal-2 $\mathrm{KO}$ mice (Figure 2, C-E). Whereas our data indicate that Hyal-2 deficiency causes an MK-intrinsic defect in platelet production with no effect on platelet half-life, a recent study found decreased erythrocyte lifespan in Hyal-2 KO animals. ${ }^{33}$

Our data raise a number of interesting questions regarding the previously unsuspected role of intracellular HA depolymerization in MK maturation and platelet release. An increasing body of literature supports the role of HA-mediated signaling through several receptors, including CD44, RHAMM, and TLR-2 and TLR-4, all of which are expressed by MKs. ${ }^{30,57,62}$ In particular, both RHAMM and 
CD44 are differentially expressed during MK development, with RHAMM increasing sixfold and CD44 decreasing during maturation. ${ }^{63}$ Regulation of $\mathrm{p} 38$ modulates MK differentiation and maturation. ${ }^{64-66}$ HA can suppress phosphorylation of p38 in multiple cell types, either directly via CD44 or indirectly through RHAMM. ${ }^{67,68} \mathrm{We}$ also found a decrease in p38 signaling in both human and murine MKs lacking Hyal-2 (Figure 2F), suggesting that total HA levels or HA polymer size supports p38 signaling in MKs.

Stimulation of TLR-2, in mouse and human MEG01 MKs, increases expression of GATA1 and NFE2, similar to our findings in Hyal-2 KO MKs (Figure 3C), as well as release of reactive oxygen species, which are capable of degrading HA directly. ${ }^{57}$ HA therefore may function as a temporal signal during megakaryopoiesis dependent on its size. We hypothesize that during early stages as MKs increase in ploidy and size, HA biosynthesis can support maturation and DMS development mediated through TLRs and CD44. Later, during the terminal stages of proplatelet formation, where RHAMM may contribute to the organization of nascent proplatelet fields, high-molecular-weight HA must be degraded into shorter polymer lengths by Hyal-2.

In conclusion, a detailed study of megakaryopoiesis in mouse and human models lacking Hyal-2 has definitively identified a requirement for HA depolymerization in the critical stage of proplatelet formation. HA likely contributes to earlier stages of MK maturation as well. This concept is supported by the profound disruption of the megakaryocyte DMS and defective proplatelet formation in hyaluronidasedeficient MKs, the latter of which could be rescued by delivery of exogenous hyaluronidase.

Disorders of thrombopoiesis are heterogeneous and may be genetic or acquired. Macrothrombocytopenias are the most frequent inherited form and are characterized by a reduction in platelet number and by an increase in platelet volume as observed in Hyal-2 KO mice. Retrospective studies of inherited platelet disorders have uncovered multiple cases of chronic macrothrombocytopenia of unknown origin with mild or no clinical manifestations. ${ }^{69-71} \mathrm{We}$ propose that the underlying molecular defect in some macrothrombocytopenias may be related to dysregulation of HA and Hyal-2.

\section{Acknowledgments}

We thank Dr. Judith Drazba and Cassandra Rogers for assistance with live microscopy, Mei Yin for assistance with electron microscopy, Katayoun Ayasoufi for assistance with flow cytometry, and Dr. Vincent Hascall for critical reading of the manuscript.

A.C.P. designed the research, performed experiments, analyzed results, and wrote the paper; D.R.O. and S.P.K. performed experiments; B.F. provided mice; and C.A.d.I.M. designed the research, analyzed results, and wrote the paper.

\section{Supplemental Data}

Supplemental material for this article can be found at http://dx.doi.org/10.1016/j.ajpath.2016.05.004.

\section{References}

1. Patel SR, Hartwig JH, Italiano JE Jr: The biogenesis of platelets from megakaryocyte proplatelets. J Clin Invest 2005, 115:3348-3354

2. Breton-Gorius J, Reyes F: Ultrastructure of human bone marrow cell maturation. Int Rev Cytol 1976, 46:251-321

3. Tomer A, Harker LA, Burstein SA: Purification of human megakaryocytes by fluorescence-activated cell sorting. Blood 1987, 70: $1735-1742$

4. Ebbe S, Stohlman F Jr: Megakaryocytopoiesis in the rat. Blood 1965, $26: 20-35$

5. Eckly A, Heijnen H, Pertuy F, Geerts W, Proamer F, Rinckel JY, Leon C, Lanza F, Gachet C: Biogenesis of the demarcation membrane system (DMS) in megakaryocytes. Blood 2014, 123:921-930

6. Mahaut-Smith MP, Thomas D, Higham AB, Usher-Smith JA, Hussain JF, Martinez-Pinna J, Skepper JN, Mason MJ: Properties of the demarcation membrane system in living rat megakaryocytes. Biophys J 2003, 84:2646-2654

7. Schulze H, Korpal M, Hurov J, Kim SW, Zhang J, Cantley LC, Graf T, Shivdasani RA: Characterization of the megakaryocyte demarcation membrane system and its role in thrombopoiesis. Blood 2006, 107:3868-3875

8. Kaufman RM, Airo R, Pollack S, Crosby WH: Circulating megakaryocytes and platelet release in the lung. Blood 1965, 26:720-731

9. Harker LA, Finch CA: Thrombokinetics in man. J Clin Invest 1969 48:963-974

10. Trowbridge EA, Martin JF, Slater DN, Kishk YT, Warren CW, Harley PJ, Woodcock B: The origin of platelet count and volume. Clin Phys Physiol Meas 1984, 5:145-170

11. Italiano JE Jr, Lecine P, Shivdasani RA, Hartwig JH: Blood platelets are assembled principally at the ends of proplatelet processes produced by differentiated megakaryocytes. J Cell Biol 1999, 147:1299-1312

12. Balazs E, Denlinger J: Sodium hyaluronate and joint function. JEVS $1985,5: 217-228$

13. Granger HJ, Barnes GE, Lewis RE: Dynamics and control of transmicrovascular fluid exchange. Edema 1984, 8:189-224

14. Toole BP: Hyaluronan: from extracellular glue to pericellular cue Nat Rev Cancer 2004, 4:528-539

15. Lesley J, Hascall VC, Tammi M, Hyman R: Hyaluronan binding by cell surface CD44. J Biol Chem 2000, 275:26967-26975

16. Hill DR, Kessler SP, Rho HK, Cowman MK, de la Motte CA: Specific-sized hyaluronan fragments promote expression of human $\beta$-defensin 2 in intestinal epithelium. J Biol Chem 2012, 287: 30610-30624

17. Slevin M, Krupinski J, Gaffney J, Matou S, West D, Delisser H, Savani RC, Kumar S: Hyaluronan-mediated angiogenesis in vascular disease: uncovering RHAMM and CD44 receptor signaling pathways. Matrix Biol 2007, 26:58-68

18. Jiang D, Liang J, Fan J, Yu S, Chen S, Luo Y, Prestwich GD, Mascarenhas MM, Garg HG, Quinn DA, Homer RJ, Goldstein DR, Bucala R, Lee PJ, Medzhitov R, Noble PW: Regulation of lung injury and repair by Toll-like receptors and hyaluronan. Nat Med 2005, 11 : 1173-1179

19. Nakamura K, Yokohama S, Yoneda M, Okamoto S, Tamaki Y, Ito T, Okada M, Aso K, Makino I: High, but not low, molecular weight hyaluronan prevents T-cell-mediated liver injury by reducing proinflammatory cytokines in mice. J Gastroenterol 2004, 39:346-354

20. Davis GE, Bayless KJ, Davis MJ, Meininger GA: Regulation of tissue injury responses by the exposure of matricryptic sites within extracellular matrix molecules. Am J Pathol 2000, 156:1489-1498 
21. Lokeshwar VB, Selzer MG: Differences in hyaluronic acid-mediated functions and signaling in arterial, microvessel, and vein-derived human endothelial cells. J Biol Chem 2000, 275:27641-27649

22. Hamad OA, Ekdahl KN, Nilsson PH, Andersson J, Magotti P, Lambris JD, Nilsson B: Complement activation triggered by chondroitin sulfate released by thrombin receptor-activated platelets. J Thromb Haemost 2008, 6:1413-1421

23. Rai SK, Duh FM, Vigdorovich V, Danilkovitch-Miagkova A, Lerman MI, Miller AD: Candidate tumor suppressor HYAL2 is a glycosylphosphatidylinositol (GPI)-anchored cell-surface receptor for jaagsiekte sheep retrovirus, the envelope protein of which mediates oncogenic transformation. Proc Natl Acad Sci U S A 2001, 98:4443-4448

24. Andre B, Duterme C, Van Moer K, Mertens-Strijthagen J, Jadot M, Flamion B: Hyal2 is a glycosylphosphatidylinositol-anchored, lipid raft-associated hyaluronidase. Biochem Biophys Res Commun 2011, 411:175-179

25. Lepperdinger G, Strobl B, Kreil G: HYAL2, a human gene expressed in many cells, encodes a lysosomal hyaluronidase with a novel type of specificity. J Biol Chem 1998, 273:22466-22470

26. Strobl B, Wechselberger C, Beier DR, Lepperdinger G: Structural organization and chromosomal localization of Hyal2, a gene encoding a lysosomal hyaluronidase. Genomics 1998, 53:214-219

27. Harada H, Takahashi M: CD44-dependent intracellular and extracellular catabolism of hyaluronic acid by hyaluronidase- 1 and -2 . J Biol Chem 2007, 282:5597-5607

28. Jadin L, Wu X, Ding H, Frost GI, Onclinx C, Triggs-Raine B, Flamion B: Skeletal and hematological anomalies in HYAL2deficient mice: a second type of mucopolysaccharidosis IX? FASEB J 2008, 22:4316-4326

29. Chowdhury B, Hemming R, Hombach-Klonisch S, Flamion B, Triggs-Raine B: Murine hyaluronidase 2 deficiency results in extracellular hyaluronan accumulation and severe cardiopulmonary dysfunction. J Biol Chem 2013, 288:520-528

30. Currao M, Malara A, Di Buduo CA, Abbonante V, Tozzi L, Balduini A: Hyaluronan based hydrogels provide an improved model to study megakaryocyte-matrix interactions. Exp Cell Res 2016, 346: $1-8$

31. de la Motte C, Nigro J, Vasanji A, Rho H, Kessler S, Bandyopadhyay S, Danese S, Fiocchi C, Stern R: Platelet-derived hyaluronidase 2 cleaves hyaluronan into fragments that trigger monocyte-mediated production of proinflammatory cytokines. Am J Pathol 2009, 174:2254-2264

32. Albeiroti S, Ayasoufi K, Hill DR, Shen B, de la Motte CA: Platelet hyaluronidase-2: an enzyme that translocates to the surface upon activation to function in extracellular matrix degradation. Blood 2015, 125:1460-1469

33. Onclinx C, Dogne S, Jadin L, Andris F, Grandfils C, Jouret F, Mullier F, Flamion B: Deficiency in mouse hyaluronidase 2: a new mechanism of chronic thrombotic microangiopathy. Haematologica 2015, 100:1023-1030

34. Levine RF, Fedorko ME: Isolation of intact megakaryocytes from guinea pig femoral marrow. Successful harvest made possible with inhibitions of platelet aggregation; enrichment achieved with a twostep separation technique. J Cell Biol 1976, 69:159-172

35. Cowman MK, Chen CC, Pandya M, Yuan H, Ramkishun D, LoBello J, Bhilocha S, Russell-Puleri S, Skendaj E, Mijovic J, Jing W: Improved agarose gel electrophoresis method and molecular mass calculation for high molecular mass hyaluronan. Anal Biochem 2011, 417:50-56

36. Schindelin J, Arganda-Carreras I, Frise E, Kaynig V, Longair M, Pietzsch T, Preibisch S, Rueden C, Saalfeld S, Schmid B, Tinevez JY, White DJ, Hartenstein V, Eliceiri K, Tomancak P, Cardona A: Fiji: an open-source platform for biological-image analysis. Nat Methods 2012, 9:676-682

37. Jurak Begonja A, Hoffmeister KM, Hartwig JH, Falet H: FlnA-null megakaryocytes prematurely release large and fragile platelets that circulate poorly. Blood 2011, 118:2285-2295
38. Eliades A, Papadantonakis N, Ravid K: New roles for cyclin E in megakaryocytic polyploidization. J Biol Chem 2010, 285: 18909-18917

39. Livak KJ, Schmittgen TD: Analysis of relative gene expression data using real-time quantitative PCR and the $2(-\Delta \Delta \mathrm{C}(\mathrm{T}))$ method Methods 2001, 25:402-408

40. Imai T, Koike K, Kubo T, Kikuchi T, Amano Y, Takagi M, Okumura N, Nakahata T: Interleukin-6 supports human megakaryocytic proliferation and differentiation in vitro. Blood 1991, 78: 1969-1974

41. Weisdorf DJ, DeFor T, Nichol J, Panoskaltsis-Mortari A, Blazar BR: Thrombopoietic cytokines in relation to platelet recovery after bone marrow transplantation. Bone Marrow Transplant 2000, 25:711-715

42. Kaushansky K: The molecular mechanisms that control thrombopoiesis. J Clin Invest 2005, 115:3339-3347

43. Kaluzhny Y, Hechler B, Lu J, Nguyen HG, Cataldo LM, Ravid K: A selective effect of $\mathrm{Mpl}$ ligand on mRNA stabilization during megakaryocyte differentiation. FEBS Lett 2002, 527:279-283

44. Zhang Y, Sun S, Wang Z, Thompson A, Kaluzhny Y, Zimmet J, Ravid K: Signaling by the Mpl receptor involves IKK and NF-кB. J Cell Biochem 2002, 85:523-535

45. Deutsch VR, Tomer A: Megakaryocyte development and platelet production. Br J Haematol 2006, 134:453-466

46. Saur SJ, Sangkhae V, Geddis AE, Kaushansky K, Hitchcock IS: Ubiquitination and degradation of the thrombopoietin receptor c-Mpl. Blood 2010, 115:1254-1263

47. Kuter DJ, Rosenberg RD: The reciprocal relationship of thrombopoietin (c-Mpl ligand) to changes in the platelet mass during busulfan-induced thrombocytopenia in the rabbit. Blood 1995, 85: $2720-2730$

48. Koshiishi I, Shizari M, Underhill CB: CD44 can mediate the adhesion of platelets to hyaluronan. Blood 1994, 84:390-396

49. Bourguignon LY, Singleton PA, Diedrich F, Stern R, Gilad E: CD44 interaction with $\mathrm{Na}+-\mathrm{H}+$ exchanger (NHE1) creates acidic microenvironments leading to hyaluronidase- 2 and cathepsin $\mathrm{B}$ activation and breast tumor cell invasion. J Biol Chem 2004, 279:26991-27007

50. Schmits R, Filmus J, Gerwin N, Senaldi G, Kiefer F, Kundig T, Wakeham A, Shahinian A, Catzavelos C, Rak J, Furlonger C, Zakarian A, Simard JJ, Ohashi PS, Paige CJ, Gutierrez-Ramos JC, Mak TW: CD44 regulates hematopoietic progenitor distribution, granuloma formation, and tumorigenicity. Blood 1997, 90:2217-2233

51. Khaldoyanidi S, Moll J, Karakhanova S, Herrlich P, Ponta H: Hyaluronate-enhanced hematopoiesis: two different receptors trigger the release of interleukin-1beta and interleukin- 6 from bone marrow macrophages. Blood 1999, 94:940-949

52. Tomer A, Harker LA, Burstein SA: Flow cytometric analysis of normal human megakaryocytes. Blood 1988, 71:1244-1252

53. Orkin SH, Zon LI: Hematopoiesis: an evolving paradigm for stem cell biology. Cell 2008, 132:631-644

54. Elagib KE, Racke FK, Mogass M, Khetawat R, Delehanty LL, Goldfarb AN: RUNX1 and GATA-1 coexpression and cooperation in megakaryocytic differentiation. Blood 2003, 101:4333-4341

55. Lecine P, Blank V, Shivdasani R: Characterization of the hematopoietic transcription factor NF-E2 in primary murine megakaryocytes. J Biol Chem 1998, 273:7572-7578

56. Rosel M, Khaldoyanidi S, Zawadzki V, Zoller M: Involvement of CD44 variant isoform v10 in progenitor cell adhesion and maturation. Exp Hematol 1999, 27:698-711

57. Beaulieu LM, Lin E, Morin KM, Tanriverdi K, Freedman JE: Regulatory effects of TLR2 on megakaryocytic cell function. Blood 2011, 117:5963-5974

58. Mauch P, Constine L, Greenberger J, Knospe W, Sullivan J, Liesveld JL, Deeg HJ: Hematopoietic stem cell compartment: acute and late effects of radiation therapy and chemotherapy. Int J Radiat Oncol Biol Phys 1995, 31:1319-1339

59. Lecine P, Villeval JL, Vyas P, Swencki B, Xu Y, Shivdasani RA: Mice lacking transcription factor NF-E2 provide in vivo validation of 
the proplatelet model of thrombocytopoiesis and show a platelet production defect that is intrinsic to megakaryocytes. Blood 1998, 92: $1608-1616$

60. Iwasaki H, Mizuno S, Wells RA, Cantor AB, Watanabe S, Akashi K: GATA-1 converts lymphoid and myelomonocytic progenitors into the megakaryocyte/erythrocyte lineages. Immunity 2003, 19:451-462

61. Strassel C, Eckly A, Leon C, Petitjean C, Freund M, Cazenave JP, Gachet C, Lanza F: Intrinsic impaired proplatelet formation and microtubule coil assembly of megakaryocytes in a mouse model of Bernard-Soulier syndrome. Haematologica 2009, 94:800-810

62. Ward JR, Bingle L, Judge HM, Brown SB, Storey RF, Whyte MK, Dower SK, Buttle DJ, Sabroe I: Agonists of toll-like receptor (TLR)2 and TLR4 are unable to modulate platelet activation by adenosine diphosphate and platelet activating factor. Thromb Haemost 2005, 94: $831-838$

63. Sun S, Wang W, Latchman Y, Gao D, Aronow B, Reems JA: Expression of plasma membrane receptor genes during megakaryocyte development. Physiol Genomics 2013, 45:217-227

64. Conde I, Pabon D, Jayo A, Lastres P, Gonzalez-Manchon C: Involvement of ERK1/2, p38 and PI3K in megakaryocytic differentiation of K562 cells. Eur J Haematol 2010, 84:430-440

65. Desterke C, Bilhou-Nabera C, Guerton B, Martinaud C, Tonetti C, Clay D, Guglielmelli P, Vannucchi A, Bordessoule D, Hasselbalch H, Dupriez B, Benzoubir N, Bourgeade MF, Pierre-Louis O, Lazar V, Vainchenker W, Bennaceur-Griscelli A, Gisslinger H, Giraudier S,
Le Bousse-Kerdiles MC; French Intergroup of Myeloproliferative Disorders, French INSERM, European EUMNET Networks on Myelofibrosis: FLT3-mediated p38-MAPK activation participates in the control of megakaryopoiesis in primary myelofibrosis. Cancer Res 2011, 71:2901-2915

66. Jacquel A, Herrant M, Defamie V, Belhacene N, Colosetti P, Marchetti S, Legros L, Deckert M, Mari B, Cassuto JP, Hofman P, Auberger P: A survey of the signaling pathways involved in megakaryocytic differentiation of the human K562 leukemia cell line by molecular and c-DNA array analysis. Oncogene 2006, 25:781-794

67. Washio A, Kitamura C, Jimi E, Terashita M, Nishihara T: Mechanisms involved in suppression of NGF-induced neuronal differentiation of PC12 cells by hyaluronic acid. Exp Cell Res 2009, 315: 3036-3043

68. Yasuda T: Hyaluronan inhibits p38 mitogen-activated protein kinase via the receptors in rheumatoid arthritis chondrocytes stimulated with fibronectin fragment. Clin Rheumatol 2010, 29:1259-1267

69. Najean Y, Lecompte T, Ardaillou N, Faille A, Dufour V: Genetic thrombocytopenia with an autosomal dominant transmission: a study of 54 cases. Nouv Rev Fr Hematol 1990, 32:67-70

70. Behrens WE: Mediterranean macrothrombocytopenia. Blood 1975 , 46:199-208

71. Veneri D, Franchini M, Randon F, Nichele I, Pizzolo G, Ambrosetti A: Thrombocytopenias: a clinical point of view. Blood Transfus 2009, 7:75-85 